\title{
Reply to: Antidepressant Actions of Ketamine Versus Hydroxynorketamine
}

\author{
Panos Zanos, Ruin Moaddel, Patrick J. Morris, Irving W. Wainer, Edson X. Albuquerque, \\ Scott M. Thompson, Craig J. Thomas, Carlos A. Zarate Jr., and Todd D. Gould \\ Departments of Psychiatry (PZ, SMT, TDG), Epidemiology and Public Health (EXA), Division of \\ Translational Toxicology, Pharmacology (EXA, TDG), Physiology (SMT), Anatomy and \\ Neurobiology (TDG), and Medicine (EXA), University of Maryland School of Medicine, and the \\ Biomedical Research Center (RM), National Institute on Aging, National Institutes of Health, \\ Baltimore; Division of Preclinical Innovation (PJM, CJT), National Center for Advancing \\ Translational Sciences, National Institutes of Health, Rockville; Experimental Therapeutics and \\ Pathophysiology Branch (CAZ), Intramural Research Program, National Institute of Mental Health, \\ National Institutes of Health, Bethesda, Maryland; and Mitchell Woods Pharmaceuticals (IWW), \\ Shelton, Connecticut.
}

\section{To the Editor}

We recently published a report in Nature describing the antidepressant actions of $(2 S, 6 S)$ and $(2 R, 6 R)$-hydroxynorketamine (HNK), which are metabolites of $S$ - and $R$-ketamine, respectively (1). In humans, $S$ - and $R$-ketamine are rapidly metabolized and cleared, with more sustained levels of HNKs (2). We provided evidence that the metabolic breakdown of $(R, S)$-ketamine is essential for its antidepressant effects in mice, and that $(2 S, 6 S)$ - and (2R, $6 R$ )-HNK independently exert antidepressant actions that do not require $N$-methyl-Daspartate receptor (NMDAR) inhibition (1). The antidepressant actions of the $(2 R, 6 R)$-HNK stereoisomer involve early and sustained activation of a-amino-3-hydroxy-5-methyl-4isoxazole propionic acid receptors (AMPARs) (1).

In their letter to Biological Psychiatry, Collingridge et al. argue that our studies, conducted using mice, have inherent difficulties in the translation to therapeutic mechanism in humans (3). We agree with this point; the clinical validation of the antidepressant actions of ketamine metabolites in humans using an investigational new drug-approved HNK metabolite is currently in preparation. Collingridge et al. also express concerns about our finding showing that $R$-ketamine is more potent than $S$-ketamine in a number of mouse models of depression. While they acknowledge that $R$-ketamine is less potent than $S$-ketamine as an NMDAR antagonist (by about two- to fourfold in vitro), they argue that there is uncertainty when estimating the brain concentrations of ketamine. We included measurements of brain ketamine levels after administration of each of these enantiomers (Extended Data Figure

Address correspondence to Todd D. Gould, M.D., Department of Psychiatry, University of Maryland School of Medicine, Room 934D MSTF, 685 W. Baltimore St., Baltimore, MD 21201; gouldlab@me.com.

Disclosures

All other authors report no biomedical financial interests or potential conflicts of interest. 
2C). We showed that the levels of ketamine after administration of equivalent doses of $R$ versus $S$-ketamine do not differ. In addition, Collingridge et al. claim that in recent clinical trials, $S$-ketamine was found roughly twice as potent as racemic $(R, S)$-ketamine. While it would be straightforward to assess for superiority of $S$-ketamine versus $(R, S)$-ketamine in a clinical trial, the results of such a study have not been reported. Singh et al. (referenced by Collingridge et al. to support their argument) showed that doses of 0.2 and $0.4 \mathrm{mg} / \mathrm{kg} S$ ketamine, administered intravenously, were comparable in regards to antidepressant effects in humans, and while both were superior to placebo, $(R, S)$-ketamine was not included in this study as a comparator (4). Most published clinical trials using $(R, S)$-ketamine for the treatment of depression used the single dose of $0.5 \mathrm{mg} / \mathrm{kg}$ (administered via intravenous infusion) (5-11), and it is therefore not yet certain whether racemic ketamine would be also effective at a lower dose (e.g., $0.2 \mathrm{mg} / \mathrm{kg}$ ). Future clinical trials may determine the lowest antidepressant effective dose of $(R, S)$-ketamine, and it will be revealing to directly compare potency of $R$-versus $S$-ketamine in a human study. However, at this point the conclusion that $S$-ketamine is twice as potent as racemic $(R, S)$-ketamine for the treatment of human depression is not supported by the scientific literature.

Our finding of a superiority of $R$-ketamine versus $S$-ketamine in animal models of depression is in line with previous studies by Hashimoto et al. revealing that $R$-ketamine has greater potency and longer-lasting antidepressant behavioral, biochemical, and cellular actions compared with $S$-ketamine in several models of depression $(12,13)$. Importantly, in agreement with the clinical findings of antidepressant effects of $S$-ketamine (4), we reported antidepressant effects of $S$-ketamine in the learned helplessness paradigm 24 hours postinjection (Figure 1D) (1). However, these antidepressant effects required higher concentrations of $S$-ketamine compared with $R$-ketamine. Moreover, our data also revealed antidepressant actions of the $S$-ketamine metabolite $(2 S, 6 S)$-HNK (Extended Data Figure $5 \mathrm{~B}, \mathrm{D})$. Although these antidepressant actions occurred at higher doses than those of ( $2 R$, $6 R)$-HNK, $(2 S, 6 S)$-HNK also lacks NMDAR inhibition properties at a concentration of 10 $\mathrm{mM}$ (Figure 3A-C). We therefore propose that the antidepressant effects of $S$-ketamine cannot be explained solely by NMDAR inhibition, and that they depend upon ketamine's metabolism to HNKs, and in particular (2S,6S)-HNK.

Collingridge et al. also suggest that the lack of sustained antidepressant effects of MK-801 observed in our studies is not a direct evidence to support an NMDAR inhibition independent antidepressant effect of $(R, S)$-ketamine because MK-801 has a different NMDAR binding affinity and pharmacokinetic profile than $(R, S)$-ketamine. Although different NMDAR channel blockers could have been used in addition to MK-801 to support our hypotheses, some of these antagonists have failed to exert antidepressant actions similar to $(R, S)$-ketamine in clinical trials (e.g., AZD6765) (14) or have proven clinically ineffective (e.g., memantine) (15). The GluN2B receptor antagonist CP-101,606 did not result in rapid antidepressant effects at 2 days, but only significantly improved Montgomery-Åsberg Depression Rating Scale scores at 5 and 8 days posttreatment (a finding which has yet to be replicated) (16), which contrasts with the rapid antidepressant effects of $(R, S)$-ketamine. Another GluN2B receptor antagonist, MK-0657/CERC-301, has recently failed phase II trials for depression (17). Indeed, a recent meta-analysis concluded that NMDAR antagonists other than $(R, S)$-ketamine have failed to show consistent efficacy for the 
treatment of depression (18). To more specifically assess the involvement of NMDAR inhibition in the antidepressant actions of $(R, S)$-ketamine, we deuterated $(R, S)$-ketamine at the 6-position of the cyclohexanone ring, which resulted in a compound that has the same binding affinity for the NMDAR as $(R, S)$-ketamine (Extended Data Figure $2 \mathrm{~F}, \mathrm{G})$, but hinders its metabolism to $(2 S, 6 S ; 2 R, 6 R)$-HNK (Figure $2 \mathrm{H}$ ) since the carbon-deuterium bond strength is significantly enhanced owing to the difference in zero-point vibrational energy. Deuterium does not change the mechanism of action, target binding affinity, cellular activity, pharmacology, pharmacokinetic/pharmacodynamic relationship, permeability, crystallinity, solubility, central nervous system tolerability, blood-brain barrier penetration, or volume of distribution of a molecule (19). We showed that deuterated ketamine lacked the 24-hour antidepressant effects in both the forced-swim and learned helplessness tests (Figure 2I, J), strongly supporting the conclusions that NMDAR inhibition alone is not sufficient to result in the unique antidepressant effects of $(R, S)$-ketamine in animal models, and metabolism of ketamine is required for its full antidepressant actions.

Finally, Collingridge et al. express concerns regarding the concentration of $10 \mu \mathrm{M}$ used in our experiments to assess the effects of $(2 R, 6 R)$-HNK on AMPAR transmission in rat hippocampal slices. Indeed, the concentration we used for these experiments is approximately sixtyfold higher than the plasma $\mathrm{C}_{\max }$ observed in bipolar depressed patients $(0.16 \mu \mathrm{M})$ receiving $0.5 \mathrm{mg} / \mathrm{kg}$ of $(R, S)$-ketamine administered intravenously over 40 minutes (2), and approximately 3.5-fold higher than the $\mathrm{C}_{\max }$ observed in mice $(2.82 \mu \mathrm{M})$ receiving $10 \mathrm{mg} / \mathrm{kg}(R, S)$-ketamine intraperitoneally (1). However, brain levels of (2S, $6 S$; $2 R, 6 R)$-HNK in humans undergoing $(R, S)$-ketamine treatment are unknown, and therefore a direct comparison of in vitro slice data to in vivo human brain concentrations is not feasible. There are also no data available regarding the pharmacokinetics of $(R, S)$-ketamine administered intraperitoneally to humans to compare to our mouse pharmacokinetic data after intraperitoneal administration. Nevertheless, at therapeutically effective doses of ketamine, the total plasma $(2 S, 6 S ; 2 R, 6 R)$-HNK exposure is 2.5 -fold higher in humans (administered intravenously; $0.5 \mathrm{mg} / \mathrm{kg}$ over 40 minutes) compared to mice $(10 \mathrm{mg} / \mathrm{kg}$ intraperitoneally; 1372 vs. $535 \mathrm{ng} / \mathrm{mL}$ per hour, respectively). Overall, these differences are not unexpected because in addition to the different route and time course of administration there are significant pharmacokinetic and pharmacodynamic differences between rodents and humans. Finally, we note that the robust and persistent increase in AMPAR field excitatory postsynaptic potential slope ( $600 \%$ of baseline; Figure $3 \mathrm{D})$ produced by $10 \mu \mathrm{M}$ $(2 R, 6 R)$-HNK suggests the likelihood that a significantly lower concentration exerts similar effects, likely of lower magnitude.

Consistent with previous reports (20-22), we showed that AMPARs have a critical role in the antidepressant effects of $(R, S)$-ketamine. In particular, our experiments revealed that blocking AMPAR activity prevented the $(2 R, 6 R)$-HNK-induced increase in electroencephalogram gamma frequency oscillations (Extended Data Figure 7I) and both the acute and persistent antidepressant behavioral actions of $(R, S)$-ketamine and $(2 R, 6 R)$-HNK (Figure $3 \mathrm{G}, \mathrm{H}$ and $4 \mathrm{H}$ ). These data suggest that the rapid potentiation of AMPAR-mediated excitation (Figure 3D-F) drives high-frequency neuronal activity, which is responsible for the unique antidepressant effects of $(R, S)$-ketamine via its metabolism to HNKs. In agreement with the suggestion of Collingridge et al., this hypothesis predicts that HNK- 
mediated high-frequency correlated neuronal activity, which underlies electroencephalogram gamma oscillations, induces activity-dependent strengthening of excitatory synapses in limbic circuits, including medial prefrontal cortex, hippocampus, and ventral striatum (23).

\section{Acknowledgments}

This work was supported by National Institutes of Health Grant Nos. MH107615 (to TDG) and MH086828 (to SMT), and the National Institute on Aging (RM, IWW), National Institute of Mental Health (CAZ), and National Center for Advancing Translational Sciences (CJT) National Institutes of Health intramural research programs.

TDG has received consulting fees from Janssen Pharmaceuticals and research funding from Janssen Pharmaceuticals and Roche Pharmaceuticals during the preceding 2 years. IWW, RM, and CAZ are listed as coinventors on a patent for the use of $(2 R, 6 R)$-hydroxynorketamine, $S$-dehydronorketamine, and other stereoisomeric dehydro- and hydroxylated metabolites of $(R, S)$-ketamine metabolites in the treatment of depression and neuropathic pain. IWW, CAZ, RM, TG, PZ, CT, and PM are listed as co-inventors on a patent application for the use of $(2 R, 6 R)$-hydroxynorketamine and $(2 S, 6 S)$-hydroxynorketamine in the treatment of depression, anxiety, anhedonia, suicidal ideation, and posttraumatic stress disorders. IWW, CAZ, RM, CT, and PM have assigned their patent rights to the U.S. government but will share a percentage of any royalties that may be received by the government. TG and PZ have assigned their patent rights to the University of Maryland Baltimore but will share a percentage of any royalties that may be received by the University of Maryland Baltimore.

\section{References}

1. Zanos P, Moaddel R, Morris PJ, Georgiou P, Fischell J, Elmer GI, et al. NMDAR inhibitionindependent antidepressant actions of ketamine metabolites. Nature. 2016; 533:481-486. [PubMed: 27144355]

2. Zarate CA Jr, Brutsche N, Laje G, Luckenbaugh DA, Venkata SL, Ramamoorthy A, et al. Relationship of ketamine's plasma metabolites with response, diagnosis, and side effects in major depression. Biol Psychiatry. 2012; 72:331-338. [PubMed: 22516044]

3. Collingridge G, Lee Y, Bortolotto Z, Kang H, Lodge D. Antidepressant actions of ketamine versus hydroxynorketamine [published online ahead of print]. Biol Psychiatry. 2016

4. Singh JB, Fedgchin M, Daly E, Xi L, Melman C, De Bruecker G, et al. Intravenous esketamine in adult treatment-resistant depression: A double-blind, double-randomization, placebo-controlled study. Biol Psychiatry. 2016; 80:424-431. [PubMed: 26707087]

5. Zarate CA Jr, Singh JB, Carlson PJ, Brutsche NE, Ameli R, Luckenbaugh DA, et al. A randomized trial of an N-methyl-D-aspartate antagonist in treatment-resistant major depression. Arch Gen Psychiatry. 2006; 63:856-864. [PubMed: 16894061]

6. Berman RM, Cappiello A, Anand A, Oren DA, Heninger GR, Charney DS, et al. Antidepressant effects of ketamine in depressed patients. Biol Psychiatry. 2000; 47:351-354. [PubMed: 10686270]

7. Diazgranados N, Ibrahim L, Brutsche NE, Newberg A, Kronstein P, Khalife S, et al. A randomized add-on trial of an N-methyl-D-aspartate antagonist in treatment-resistant bipolar depression. Arch Gen Psychiatry. 2010; 67:793-802. [PubMed: 20679587]

8. Murrough JW, Iosifescu DV, Chang LC, Al Jurdi RK, Green CE, Perez AM, et al. Antidepressant efficacy of ketamine in treatment-resistant major depression: A two-site randomized controlled trial. Am J Psychiatry. 2013; 170:1134-1142. [PubMed: 23982301]

9. Singh JB, Fedgchin M, Daly EJ, De Boer P, Cooper K, Lim P, et al. A double-blind, randomized, placebo-controlled, dose-frequency study of intravenous ketamine in patients with treatmentresistant depression. Am J Psychiatry. 2016; 173:816-826. [PubMed: 27056608]

10. Murrough JW, Perez AM, Pillemer S, Stern J, Parides MK, aan het Rot M, et al. Rapid and longerterm antidepressant effects of repeated ketamine infusions in treatment-resistant major depression. Biol Psychiatry. 2013; 74:250-256. [PubMed: 22840761]

11. Zarate CA Jr, Brutsche NE, Ibrahim L, Franco-Chaves J, Diazgranados N, Cravchik A, et al. Replication of ketamine's antidepressant efficacy in bipolar depression: A randomized controlled add-on trial. Biol Psychiatry. 2012; 71:939-946. [PubMed: 22297150] 
12. Yang C, Shirayama Y, Zhang JC, Ren Q, Yao W, Ma M, et al. R-ketamine: A rapid-onset and sustained antidepressant without psychotomimetic side effects. Transl Psychiatry. 2015; 5:e632. [PubMed: 26327690]

13. Zhang JC, Li SX, Hashimoto K. R (-)-ketamine shows greater potency and longer lasting antidepressant effects than S (+)-ketamine. Pharmacol Biochem Behav. 2014; 116:137-141. [PubMed: 24316345]

14. Sanacora G, Smith MA, Pathak S, Su HL, Boeijinga PH, McCarthy DJ, et al. Lanicemine: A lowtrapping NMDA channel blocker produces sustained antidepressant efficacy with minimal psychotomimetic adverse effects. Mol Psychiatry. 2014; 19:978-985. [PubMed: 24126931]

15. Zarate CA Jr, Singh JB, Quiroz JA, De Jesus G, Denicoff KK, Luckenbaugh DA, et al. A doubleblind, placebo-controlled study of memantine in the treatment of major depression. Am J Psychiatry. 2006; 163:153-155. [PubMed: 16390905]

16. Preskorn SH, Baker B, Kolluri S, Menniti FS, Krams M, Landen JW. An innovative design to establish proof of concept of the antidepressant effects of the NR2B subunit selective N-methyl-Daspartate antagonist, CP-101,606, in patients with treatment-refractory major depressive disorder. J Clin Psychopharmacol. 2008; 28:631-637. [PubMed: 19011431]

17. Sanacora G. What are we learning from early-phase clinical trials with glutamate targeting medications for the treatment of major depressive disorder. JAMA Psychiatry. 2016; 73:651-652. [PubMed: 27303925]

18. Newport DJ, Carpenter LL, McDonald WM, Potash JB, Tohen M, Nemeroff CB, et al. Ketamine and other NMDA antagonists: Early clinical trials and possible mechanisms in depression. Am J Psychiatry. 2015; 172:950-966. [PubMed: 26423481]

19. Gant TG. Using deuterium in drug discovery: Leaving the label in the drug. J Med Chem. 2014; 57:3595-3611. [PubMed: 24294889]

20. Autry AE, Adachi M, Nosyreva E, Na ES, Los MF, Cheng PF, et al. NMDA receptor blockade at rest triggers rapid behavioural antidepressant responses. Nature. 2011; 475:91-95. [PubMed: 21677641]

21. Li N, Lee B, Liu RJ, Banasr M, Dwyer JM, Iwata M, et al. mTOR-dependent synapse formation underlies the rapid antidepressant effects of NMDA antagonists. Science. 2010; 329:959-964. [PubMed: 20724638]

22. Maeng S, Zarate CA Jr, Du J, Schloesser RJ, McCammon J, Chen G, et al. Cellular mechanisms underlying the antidepressant effects of ketamine: Role of alpha-amino-3-hydroxy-5methylisoxazole-4-propionic acid receptors. Biol Psychiatry. 2008; 63:349-352. [PubMed: 17643398]

23. Thompson SM, Kallarackal AJ, Kvarta MD, Van Dyke AM, LeGates TA, Cai X. An excitatory synapse hypothesis of depression. Trends Neurosci. 2015; 38:279-294. [PubMed: 25887240] 